\title{
Intramedullary Spinal Cord and Intracranial Tuberculomas in HIV Infected Patient
}

Benabdellah $\mathrm{A}^{1}$, Bachir $\mathrm{N}^{2}$, Belharane $\mathrm{A}^{2}$, Benabadji $\mathrm{A}^{2}$, Benchouk $\mathrm{S}^{2}$, Bensaha $\mathrm{Z}^{2}$, Bensaad $\mathbf{M}^{2}$, Brahimi $\mathrm{H}^{2}$, Lakhdori $\mathrm{F}^{2}$, Mahamdaoui $\mathbf{F}^{2}$,Mahmoudi $\mathbf{R}^{2}$,Taleb-Bendiab $\mathbf{R}^{2}$ and Berrada $\mathbf{S}^{3}$

${ }^{1} \mathrm{HIV}$ laboratory research, University of Oran, Algeria

${ }^{2}$ CHU TLEMCEN, University of Oran, Algeria

${ }^{3} \mathrm{CHU}$ ORAN, University of Oran, Algeria

\begin{abstract}
Intramedullary spinal tuberculoma is a rare form of central nervous system tuberculosis. We report a case in HIV infected patient with evidence of symptoms of systemic tuberculosis who presented with a history of progressive leg weakness, urinary urgency, and impotence. Thoracic MRI showed disseminated micronodular lesions. Abdominal MRI revealed ascitis, necrosed retroperitoneal adenopathies. Ascitis liquid acid-fast bacilli stainings and cultures were positive. MRI of the brain revealed multiple infracentimetric nodular lesions in the cerebral parenchyma and in cerebellar vermis. MRI of spinal cord revealed two intramedullary hyper intense lesions measuring $10 \mathrm{~mm}$ and $7 \mathrm{~mm}$ interesting the terminal cones. Gd-DTPA-enhanced MRI showed enhancement of the two intramedullary lesions. The lesion, was located in the cones medullaris. Antituberculous medication was instituted as soon as the diagnosis was made. Neurologic symptoms and signs slowly improved.
\end{abstract}

Keywords: Intramedullary spinal tuberculoma; MRI; Spinal cord; Tuberculoma

\section{Introduction}

Tuberculosis is a serious health problem in underdeveloped countries and a leading cause of death. Tuberculosis can involve any body part, spinal cord involvement is rare. Central nervous system tuberculosis occurs secondary to hematogenous spread from a subclinical or radiologically occult primary, usually in the lungs. The most common form of spinal intradural tuberculosis is meningitis. The occurrence of intramedullary tuberculoma is rare. The reported incidence of intramedullary tuberculoma quoted being 2 per 100,000 cases of tuberculosis. The concurrent occurrence of cranial and intramedullary tuberculoma is rarer. Only such cases have been reported in world literature. We report one such rare case that had complete recovery with antituberculous drugs without surgical treatment.

\section{Case Report}

A 33-year-old man infected with HIV was admitted with a history of low back pain, progressive weakness, and paresthesia in the legs. $\mathrm{He}$ reported urinary urgency, impotence, and difficulty with walking in the previous 10 days. There was history of ganglionar tuberculosis in 2011.

General systemic examination, including clinical examination of the chest, revealed abnormalities of the vesicular sound. Motor testing revealed incomplete loss of dorsiflexion and bilateral weakness of plantar flexion. Sensory testing revealed hypoesthesia in the sacral dermatomas. Ankle jerks were depressed and both plantar responses were extensor.

Laboratory studies revealed a normal complete blood count. A chest plain radiograph showed micronodular miliary. Thoracic MRI (Figure 1) showed disseminted micronodular lesions. Abdominal MRI (Figure 2) revealed ascitis, necrosed retroperitoneal adenopathies. Histological examination of the specimen of ascitis revealed a granulomatous lesion containing multinucleated Langhans' giant cells, inflammatory cells, and caseating necrosis. Tuberculin skin test, with 10 units of purified protein derivative, was positive. Ascitis liquid acid-fast bacilli stainings and cultures were positive.MRI of the brain (Figure 3 ) revealed multiple infracentimetric nodular lesions in the cerebral parenchyma and in cerebellar vermis. Gd-DTPA-enhanced MRI showed enhancement of the lesions.

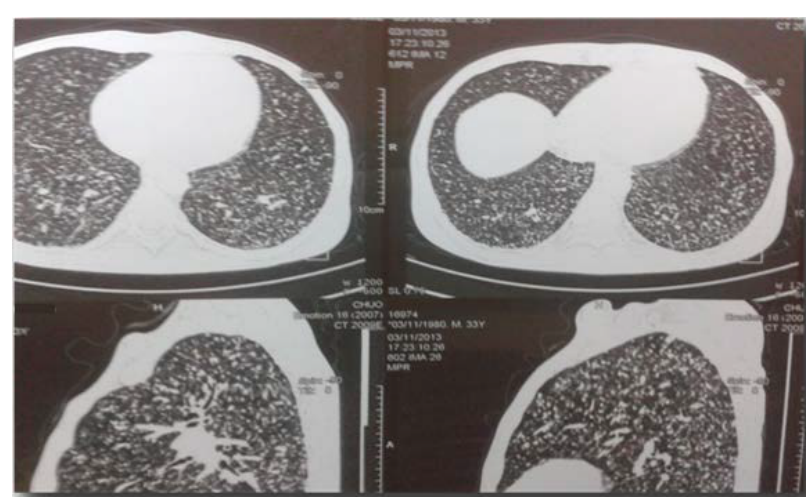

Figure 1: CT Chest showing miliary tuberculosis.

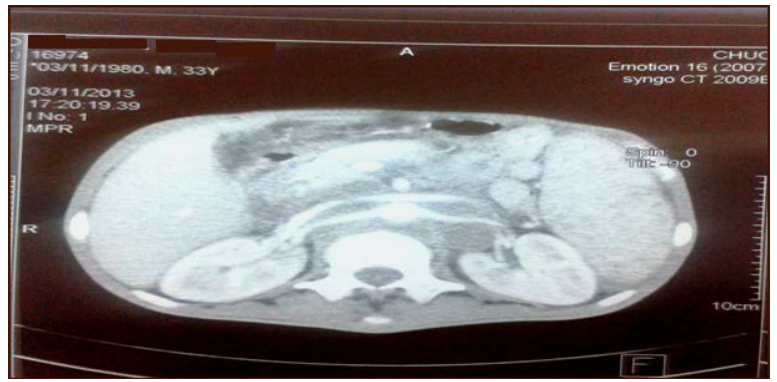

Figure 2: Thoracoabdominal CT showing multinodular spleen, ascitis and necrosed retroperitoneal adenopathies

*Corresponding author: Benabdellah A, HIV Llaboratory Research, University of Oran, PO Box 1524, El m'naouer Oran (31000) - Algeria, Tel: 00213551242992; E-mail: benabdellah_anwar@yahoo.fr

Received August 21, 2014; Accepted November 17, 2014; Published November 19, 2014

Citation: Benabdellah A, Bachir N, Belharane A, Benabadji A, Benchouk S, et al (2014) Intramedullary Spinal Cord and Intracranial Tuberculomas in HIV Infected Patient. J Spine 3: 192. doi:10.4172/2165-7939.1000192

Copyright: (C) 2014 Benabdellah A, et al. This is an open-access article distributed under the terms of the Creative Commons Attribution License, which permits unrestricted use, distribution, and reproduction in any medium, provided the original author and source are credited. 


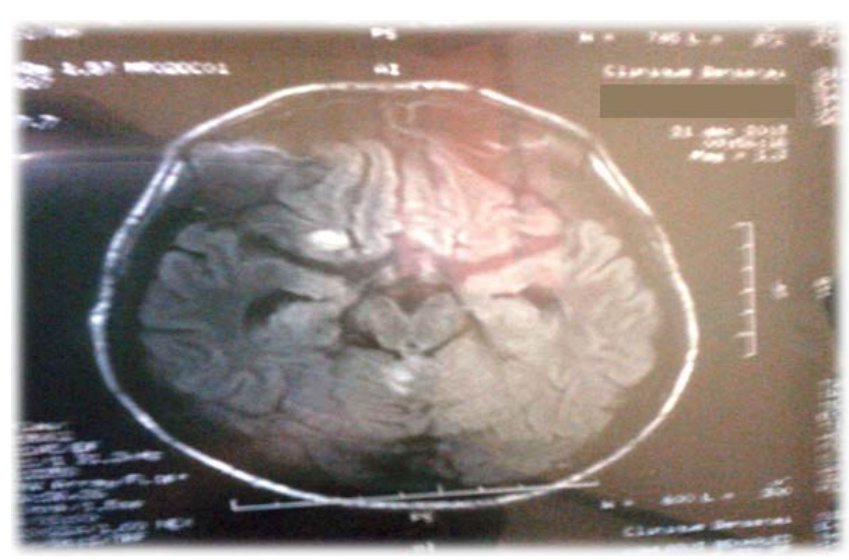

Figure 3: Cerebral MRI showing 2 nodular lesions.

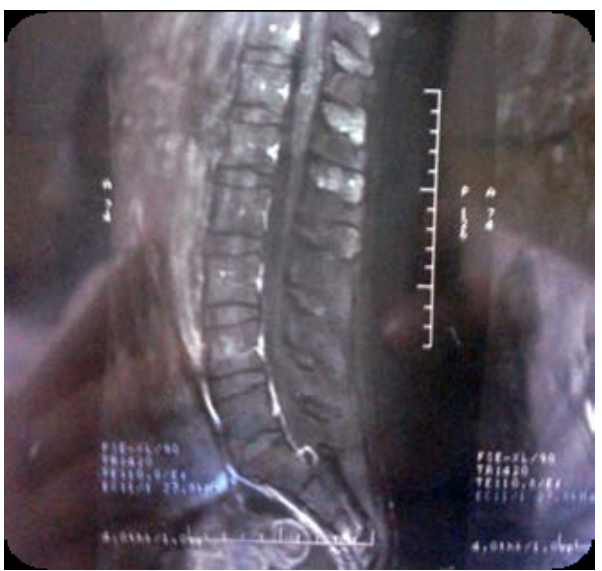

Figure 4: MRI of the spine revealed two intramedullary hyper intense lesions measuring $10 \mathrm{~mm}$ and $7 \mathrm{~mm}$ interesting the terminal conus. Gd-DTPAenhanced MRI showed enhancement of the two intramedullary lesions.

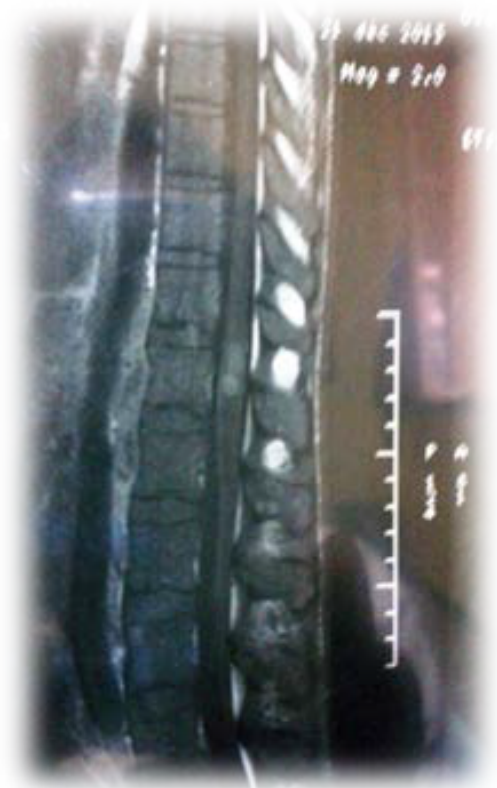

Figure 5: Mri of spinal cord: sagittal section showing 2 well defined lesions
MRI of the spine revealed two intramedullary hyper intense lesions measuring $10 \mathrm{~mm}$ and $7 \mathrm{~mm}$ interesting the terminal cones. GodDTPA-enhanced MRI showed enhancement of the two intramedullary lesions (Figures 4 and 5). Quadruple therapy with ethambutol, rifampin, isoniazid, and pyrazinamide was started. The patient's paraparesis slowly improved. At follow-up 3 months later, he was able to walk without any sexual or urinary dysfunction.

\section{Discussion}

The most common form of spinal tuberculosis is tuberculous spondylitis (Pott's disease). Meningitis is the most common form of spinal intradural tuberculosis. Tuberculomas are mainly located intracranially. Spinal tuberculomas comprise $2-5 \%$ of the all CNS tuberculomas [1].

Arseni and Samitca [2] found 210 cases of CNS tuberculoma, of which only 9 were spinal masses. Intramedullary location was found in only five of these spinal tuberculomas.

The rarity of intramedullary spinal tuberculomas was also emphasized by Citow and Ammirati in 1994 [3].

They mentioned that intramedullary tuberculomas were seen in 2 of 100,000 cases of tuberculosis and 2 of 1000 cases of CNS tuberculosis disease. Infection with HIV increases the risk of tuberculosis [4]. The first bacteriologically proven case of an intramedullary tuberculoma in a patient with HIV infection was reported by Gallant et al. in 1992 [5]. Alessi et al. reported a combined subdural tuberculous empyema and intramedullary tuberculoma in an HIV-positive patient [6]. Concurrent occurrence of intracranial tuberculomas along with intramedullary spinal tuberculoma is rarer. Huang et al. [7], Shen et al. [8] and Muthukumar [9] reported patients symptomatic for both intracranial and intramedullary tuberculomas. Thacker [10] reported a 6-yearold girl in whom imaging revealed intramedullary tuberculomas with incidentally discovered multiple intracranial tuberculomas. Yen et al. [11] reported a 67-year-old man with known pulmonary tuberculosis who developed symptoms of spinal cord compression. The CT chest of our patient was anormal with evidence of pulmonary tuberculosis. The MRI findings in the present case were typical. Iso or hypointensity of intracranial lesions of both T1 weighted and T2 weighted MR imaging are characteristic of the caseous necrotic content that is usually found in tuberculomas. Non caseous tuberculomas typically display a hypointense signal on $\mathrm{T} 1$ and a hyper intense signal on T2 weighted image, with homogenous enhancement after gadolinium administration.

MR spectroscopy of tuberculoma demonstrates lipid leaks at 0.9 , 1.3, 2.0 and $2.8 \mathrm{ppm}$; and a phosphorine peak at $3.7 \mathrm{ppm}$. The lipid peak is due to presence of fatty acids found in caseous material in the centre of tuberculoma. Antituberculous drugs with corticosteroids offer effective, safe and feasible option for treating intramedullary tuberculoma, especially in developing countries where microchirurgical techniques may not be widely available.

\section{References}

1. LIN TH (1960) Intramedullary tuberculoma of the spinal cord. J Neurosurg 17: 497-499.

2. ARSENI C, SAMITCA DC (1960) Intraspinal tuberculous granuloma. Brain 83 285-292.

3. Citow JS, Ammirati M (1994) Intramedullary tuberculoma of the spinal cord: case report. Neurosurgery 35: 327-330.

4. Villoria MF, Fortea F, Moreno S, Muñoz L, Manero M, et al. (1995) MR imaging and CT of central nervous system tuberculosis in the patient with AIDS. Radio Clin North Am 33: 805-820. 
Citation: Benabdellah A, Bachir N, Belharane A, Benabadji A, Benchouk S, et al. (2014) Intramedullary Spinal Cord and Intracranial Tuberculomas in HIV Infected Patient. J Spine 3: 192. doi:10.4172/2165-7939.1000192

5. Gallant JE, Mueller PS, McArthur JC, Chaisson RE (1992) Intramedullary tuberculoma in a patient with HIV infection. AIDS 6: 889-891.

6. Alessi G, Lemmerling M, Nathoo N (2003) Combined spinal subdural tuberculous empyema and intramedullary tuberculoma in an HIV-positive patient. Eur Radiol 13: 1899-1901.

7. Huang CR, Lui CC, Chang WN, Wu HS, Chen HJ (1999) Neuroimages of disseminated neurotuberculosis: report of one case. Clin Imaging 23: 218-222.

8. Shen WC, Cheng TY, Lee SK, Ho YJ, Lee KR (1993) Disseminated tuberculomas in spinal cord and brain demonstrated by MRI with gadoliniumDTPA. Neuroradiology 35: 213-215.
9. Muthukumar N, Venkatesh G, Senthilbabu S, Rajbaskar R (2006) Surgery for intramedullary tuberculoma of the spinal cord: report of 2 cases. Surg Neurol 66: 69-74.

10. Thacker MM, Puri Al (2004) Concurrent intra-medullary and intra-cranial tuberculomas. J Postgrad Med 50: 107-109.

11. Yen HL, Lee RJ, Lin JW, Chen HJ (2003) Multiple tuberculomas in the brain and spinal cord: a case report. Spine (Phila Pa 1976) 28: E499-502. 